Fifth International Conference on Sustainable Construction Materials and

Technologies. http://www.claisse.info/Proceedings.htm

\title{
UTILISATION OF WOOD ASH FOR ENVIRONMENTALLY FRIENDLY CONCRETE PRODUCTION
}

\author{
Sevket Can Bostanci \\ European University of Lefke, Faculty of Engineering, Department of Civil \\ Engineering, Lefke, Northern Cyprus, TR-10, Mersin, Turkey. E-mail: \\ sbostanci@eul.edu.tr
}

\begin{abstract}
Portland cement (OPC) production is responsible approximately 5\% to global $\mathrm{CO}_{2}$ emissions which is one the greenhouse gases that contributes global warming the most. The aim of cement stakeholders is to use waste products as an alternative to OPC in order to improve sustainability credentials of concrete production. Against this background, wood ash (WA) use as a replacement to OPC was considered to be an alternative approach for environmentally concrete production. Reported work carried out to evaluate the use of WA use as a partial replacement to OPC. In the light of these, OPC was replaced by WA with replacement levels of $5 \%$ and $12.5 \%$ for the production of $\mathrm{C} 35$ concrete strength class.

Results showed that WA incorporation resulted in lower performances as WA replacement level increased. However, 5\% WA incorporated concrete mix achieved similar results compared to control mix. The results also indicate promising performances for longer ages.
\end{abstract}

Keywords: Wood ash, sustainability, low carbon, strength, thermal conductivity, sulfate resistance

\section{INTRODUCTION}

Global population is expected to be 9.8 billion by the year of 2050 (United Nations, 2017). In order to accommodate the proposed population, structuring and therefore, concrete production is expected to be doubled by 2050 (Allwood, 2010). Meanwhile cement production, solely, is expected to rise to 4.4 billion tonnes (Columbia University, 2012). As a result of this, the use of waste materials instead of natural materials in concrete production has come to prominence. Meanwhile, requirement for maintaining mechanical and durability aspects of the concrete is still not at the desirable levels. Several waste materials and by products have been utilised in concrete production by the research community in order to optimise the use of these materials with optimum performance depending upon the local availability. The use of local materials is a trending approach due to lower environmental footprint through shorter transportation distances. Concrete production is mostly dependent to limited natural resources in North Cyprus construction sector. However, most of the cement used for concrete production is imported abroad, and thus, contributes to global warming 
through $\mathrm{CO}_{2}$ emissions from the production as well as the transportation. In the light of these, more environmentally friendly materials as a replacement to ordinary Portland cement (OPC) are sought to use in the concrete production but the concrete industry has not welcomed the use of waste products in concrete production due to mostly the performance requirements cannot be met when these materials are utilised. Wood ash in is one of the most common wastes in North Cyprus and there is no specific treatment for this waste. They are either rarely being used as fertilizer or mostly being landfilled. Wood ash (WA) could be a potential environmental friendly material to be used in concrete through its pozzolanic properties that contribute to overall performance at longer ages (Siddique, 2012; Ramos, 2013; da Luz Garcia, 2013). Udeoyo (2006) used WA as an additive and reported that WA addition required more water content. Abdullahi (2006) however used WA as a partial replacement with replacement levels of $10 \%, 20 \%, 30 \%$ and $40 \%$ and stated WA mixes indicated lower results compared to control mix at 28 and 60 days due to inadequate Calcium hydroxide content of WA. Naik (2002) investigated WA with replacement contents of $5 \%, 8 \%$ and $12 \%$ and found out an indication of pozzolanic activity from 28 days to 365 days. Ban (2011) reported that the use of WA with replacement level of $10 \%$ could be used for structural concrete applications.

The research described in this paper investigates the effect of WA use in concrete. For this aim, PC was replaced by wood ash, obtained from domestic heating purposes, with replacement levels of $5 \%$ and $12.5 \%$ on mass basis. A control mix and two WA incorporated mixes with 28-day design strength of C28/35 were produced. These concrete mixes were tested for basic engineering and durability properties such as hardened unit weight, compressive cube strength, ultrasonic pulse velocity, thermal conductivity, sound permeability, and resistance to sulfate.

\section{EXPERIMENTAL PROGRAMME}

\subsection{Materials}

Three different mixes were investigated in this research. Initially, a control mix made with CEM I OPC and natural aggregates. In addition, second and third mixes were cast by replacing OPC with WA with replacement levels of $5 \%$ and $12.5 \%$. OPC used was 42.5 in conformity with TS EN 197-1:2011 throughout the study. WA used in this study was obtained from a domestic house that was collected through domestic fireplace heating which was originally an olive tree. The collected WA was sieved through $425 \mu \mathrm{m}$ sieve. Crushed natural aggregates were used that obtained from local supplier. MasterGlenium 126, a Polycarboxylic ether based versatile high-range water reducer superplazticizer, was used as an admixture in conformity with TS EN 934-2.

\subsection{Mix Proportions and Concrete Mix Design}

Concrete mixes were proportioned in conformity with Building Research Establishment mix design method. Initially, trial mixes were produced then final mix proportions were determined. Concrete mixes were proportioned to have water to binder $(\mathrm{w} / \mathrm{b})$ ratio of 0.55 . The mix design is based on the average relative density of coarse aggregate to determine concrete density. The percentage of fine aggregates passing $600 \mu \mathrm{m}$ was determined through sieve analysis. The mix proportions used are provided in Table 1 that was carried out to have target consistency S3 workability class in accordance with TS EN 206:2013+A1. Both coarse and fine aggregate contents 
were kept same. In addition, total cementitious contents were also kept same. The admixture content was proportioned according to the OPC content and kept $1 \%$ of the OPC content through all mixes. Concrete mixes were designed in aiming to achieve 28-day target strength of $35 \mathrm{~N} / \mathrm{mm}^{2}$ compressive cube strength (C28/35). The first mix was a control mix made with only OPC that was stated as OPC. Second and third mixes contained $5 \%$ and $12.5 \%$ WA content as a replacement to OPC and stated as WA-5 and WA-12.5 respectively. Mix proportions are given in Table 1.

Concrete production and fresh concrete testing were carried out according to TS EN 12350:2000 Part 1 and 2. After mixing all ingredients, slump test was carried out.

Table 1. Mix proportions of concretes

\begin{tabular}{ccccccc}
\hline Mix name & $\begin{array}{c}\text { Water } \\
(\mathrm{kg})\end{array}$ & $\begin{array}{c}\text { Portland cement } \\
(\mathrm{kg})\end{array}$ & $\begin{array}{c}\text { Wood ash } \\
(\mathrm{kg})\end{array}$ & \multicolumn{2}{c}{$\begin{array}{c}\text { Aggregates } \\
(\mathrm{kg})\end{array}$} & $\begin{array}{c}\text { Admixture } \\
(\mathrm{kg})\end{array}$ \\
\hline OPC & 220 & 400 & - & Fine & Coarse & \\
WA-5 & 220 & 380 & 20 & 875 & 840 & 4.00 \\
WA-12.5 & 220 & 350 & 50 & 875 & 840 & 3.80 \\
\hline
\end{tabular}

\subsection{Test Methods}

Hardened properties were studied including compressive cube strength, ultrasonic pulse velocity (UPV), sound permeability and thermal conductivity tests. Cubes with dimensions of $150 \mathrm{~mm}$ by $150 \mathrm{~mm}$ were cast to determine the compressive strength of concretes at ages of 1, 7, 14, 28 and 56 days according to TS EN 12390-3:2009. 150 $\mathrm{mm}$ cubes were initially used for UPV tests. $500 \mathrm{~mm}$ by $500 \mathrm{~mm}$ square samples with thickness of $40 \mathrm{~mm}$ were cast for determination of sound permeability and thermal conductivity properties of concretes. $150 \mathrm{~mm}$ cubes were also cast to establish sulfate resistance at 28 and 56 days. Three samples were tested for each concrete mix.

\subsubsection{Sound Permeability Test}

Sound permeability test was carried out through fully automatic and computer controlled test equipment. The test equipment is given in Figure 1 shown below by Fore A.Ş., Turkey. 500 $\mathrm{mm} \times 500 \mathrm{~mm}$ square samples with thickness of $40 \mathrm{~mm}$ were used to test sound permeability of concretes. After casting, samples were kept in the moulds for 24 hours and then removed from the mould and water-cured for 28 days. Sound was applied through one side (given) and received through the other side (received). Samples were surrounded with polystyrene foam when sound was being applied. Continuous sound has been applied for an hour and values then were saved through specific software that shows given and received values are taken into account 1 hour intervals. All results are converted to PDF then values are averaged. The duration was kept the same for all samples in order to assess mixes under the same conditions. Sound permeability was measured at 28 and 56 days in terms of percentages through applied and received sound (in decibels). 


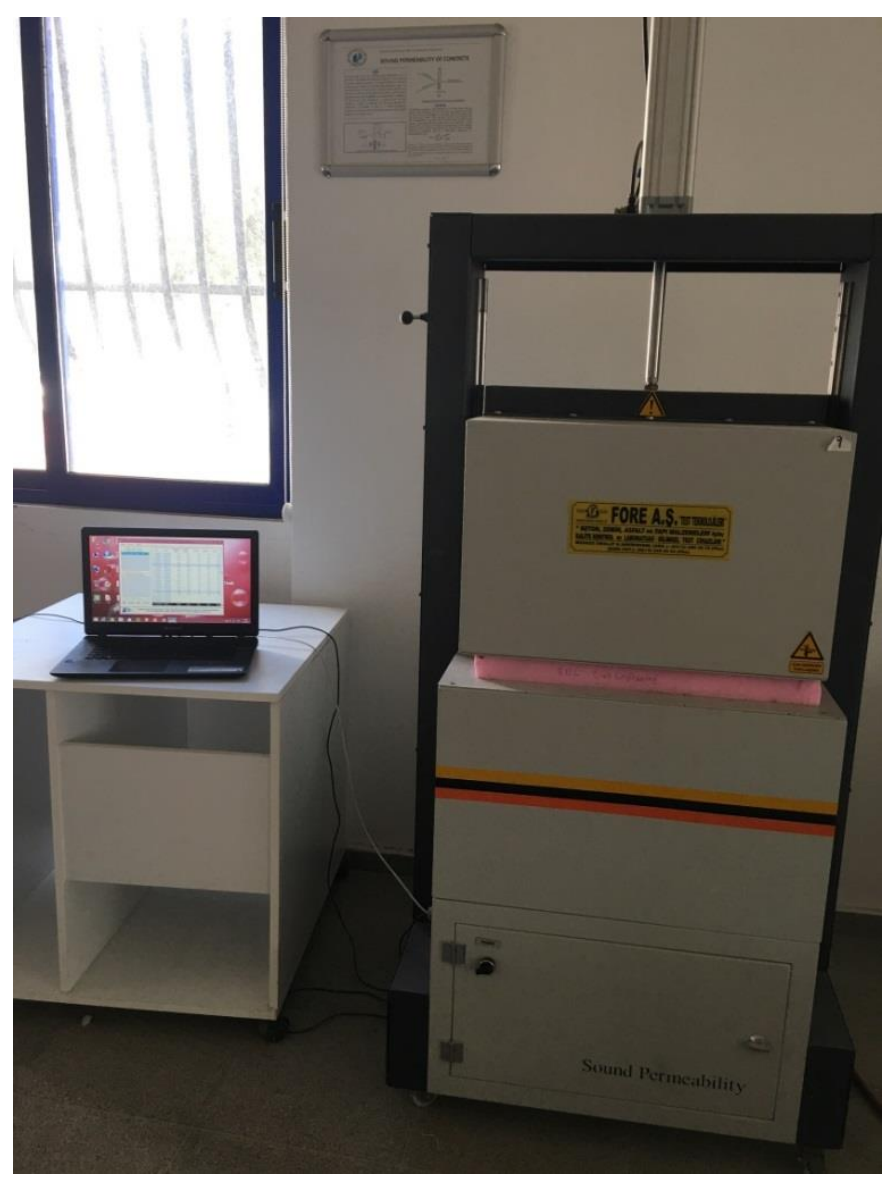

Figure 1. Sound Permeability Test Equipment

\subsubsection{Thermal Conductivity Test}

Thermal conductivity of concrete samples was determined in the same way as sound permeability test. Heat is applied though lower plate to the sample then received at upper plate. The temperature difference was set to $20^{\circ} \mathrm{C}$. Then, 1 value, that represent thermal conductivity of sample, was obtained from the test equipment considering area and thickness of sample, temperature difference between plates and power to generate temperature difference.

\subsubsection{Resistance to Sulfate}

Sulfate resistance of concrete mixes were tested at 28 days. Cubic specimens with dimensions of $150 \mathrm{~mm} \times 150 \mathrm{~mm}$ was cured for 28 days and put in the oven cured for 24 hours at $105{ }^{\circ} \mathrm{C}$ in order to remove any moist inside the sample. Samples were exposed in $50 \mathrm{~g} / \mathrm{L}$ Na2SO 4 solution and initial mass and mass after the exposure were measured and resistance to sulfate was determined.

\section{RESULTS AND DISCUSSION}

\subsection{Fresh Properties}

\subsubsection{Slump Test}

Slump test results of concrete mixes are presented in Figure 2. It could be seen from the results that incorporation of WA as a replacement to OPC resulted in decrease in 
slump value. It can be seen that the use of WA resulted in lower results for WA-5 and WA-12.5 concrete mixes which is in consistent with Siddique (Siddique, 2012). However, this reduction might be linked with the reduced admixture content of WA incorporated mixes. In addition, the slump values also showed that WA has porous characterictics and required more water content to compensate slump loss which is line with previous researches (Udeoyo, 2006; Ban Cheah, 2018 \& Usman, 2018) that WA mixes require higher water content for the same workability requirements.

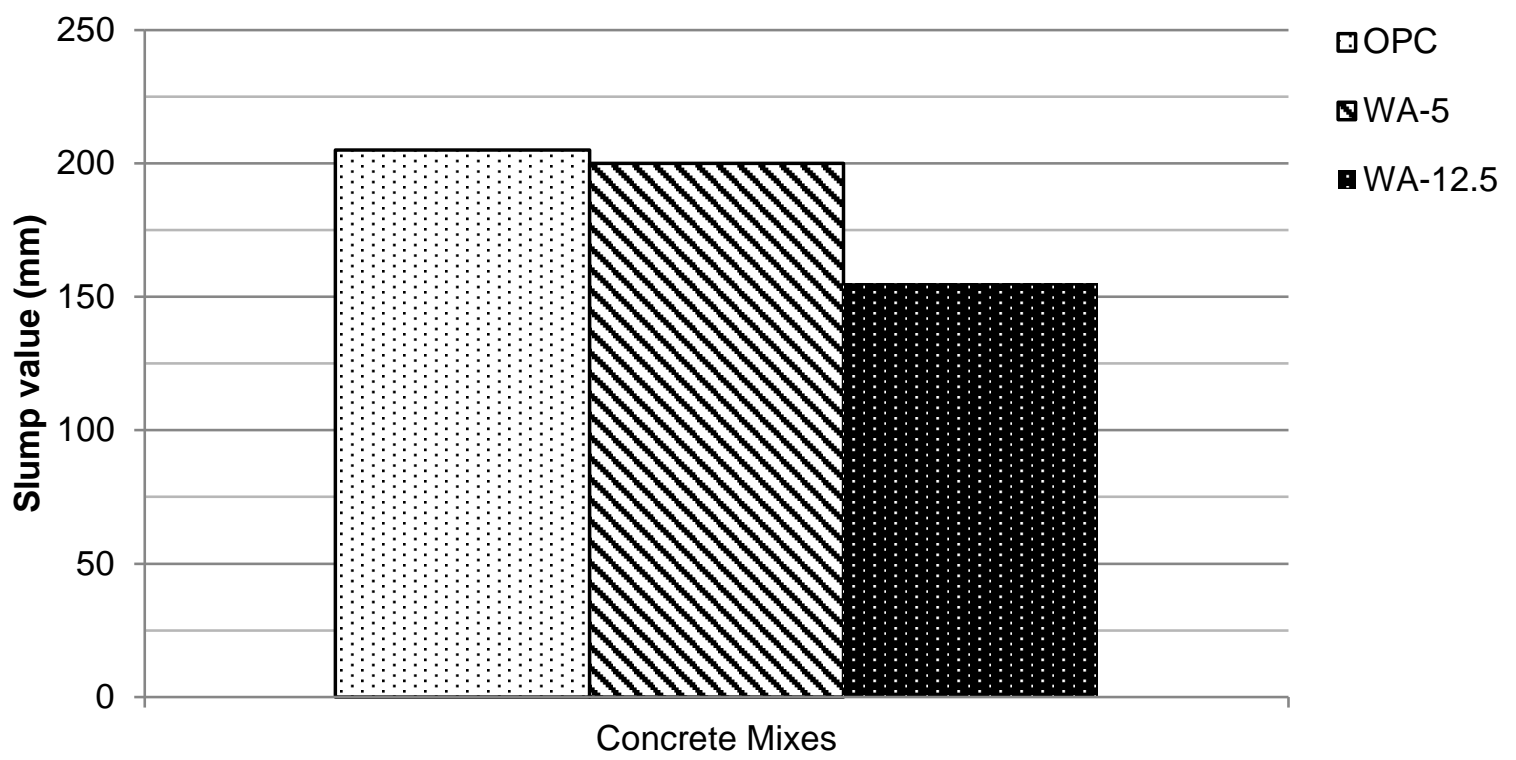

Figure 2. Slump test results

\subsubsection{Fresh Unit Weight}

Fresh unit weight test results are presented in Table 2. All mixes were observed to provide higher density values than the proposed mix design values. As can be seen from Table 2, utilisation of WA resulted in a slight reduction of unit weights of concretes. Throughout the mix design, all constituents were kept same except WA added mixes. Thus, this reduction in unit weight of WA mixes is linked with lower density of WA compared to OPC.

Table 2. Fresh unit weight results

Concrete mix Fresh Unit Weight $\left(\mathbf{k g} / \mathrm{m}^{3}\right)$

$\begin{array}{cc}\text { OPC } & 2390 \\ \text { WA-5 } & 2378 \\ \text { WA-12.5 } & 2365\end{array}$

\subsection{Hardened Properties}

\subsubsection{Hardened Unit Weight}


Hardened unit weight results of mixes are shown in Table 3. Similar trend as fresh unit weight values were observed for hardened unit weight results. In link with both fresh and hardened unit weights, it can be said that WA has slightly lower specific gravity than OPC.

Table 3. Hardened unit weight results

Concrete mix

$$
\begin{gathered}
\text { OPC } \\
\text { WA-5 } \\
\text { WA-12.5 }
\end{gathered}
$$

Hardened Unit Weight $\left(\mathrm{kg} / \mathrm{m}^{3}\right)$

2237

2222

2204

\subsubsection{Compressive Cube Strength}

Compressive cube strength results of mixes are given in Figure 3. It can be seen from the results that OPC indicated considerably higher early strength (1 and 7 days) than WA mixes. This is believed to be higher $\mathrm{CaO}$ content of OPC than WA. Strength loss for WA-5 mix was observed as 18\% at all 1,7, and 14 days, whilst 33\%, 28\% and 19\% was noted for WA-12.5 mixes at these ages. The strength loss of WA mixes at 28 days was observed to be $8 \%$ and $19 \%$ for WA-5 and WA-12.5 mixes respectively compared to OPC mix. This indicated an improvement compared to the strength losses at pre-14 days. Da Luz Garcia (2013) also reported reduction in the compressive strength as the WA content increase at 28 days. In addition to these, strength losses at 56 days were observed to be 6 and 19\% for WA-5 and WA-12.5 mixes respectively. These improvements, especially for WA-5, could be explained by pozzolanic reactions brought by WA incorporation formed extra calcium-silica-hydrate (C-S-H) gel. Moreover, existing findings (Ban, 2011; Siddique, 2012; Luz Garcia, 2013 \& Ramos, 2013) reported that mixes with WA replacement up to $10 \%$ achieved either similar or higher compressive strengths at 90 days.

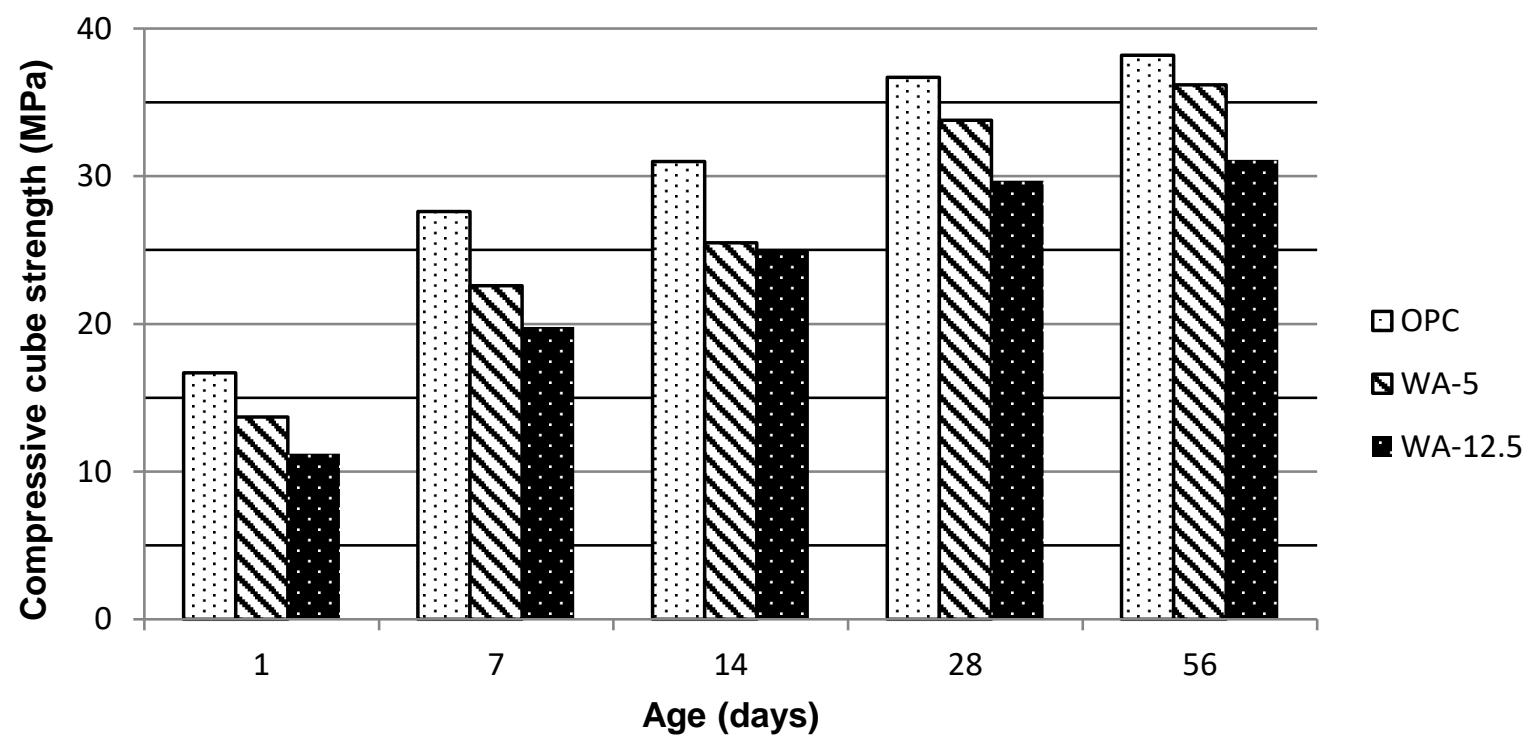

Figure 3. Compressive cube strength results 


\subsubsection{Schmidt Hammer}

Schmidt Hammer test results are presented in Table 4. At both ages, WA utilisation was observed to reduce the Schmidt hammer values as the WA increased. Figure 4 gives the ratio between the Schmidt hammer and compressive strength values. It is seen from Figure 3 that OPC mix indicated 0.90 and 0.92 at 28 and 56 days respectively. While, 0.84 and 0.79 and 0.84 and 0.92 ratios were observed for WA-5 and WA-12.5 mixes respectively at 28 and 56 days.

Table 4. Schmidt Hammer test results

\begin{tabular}{ccc}
\hline Concrete Mix & \multicolumn{2}{c}{ Compressive Strength $\left(\mathbf{N} / \mathbf{m m}^{\mathbf{2}}\right)$} \\
& 28-days & $\mathbf{5 6 - d a y s}$ \\
\hline OPC & 33 & 35 \\
WA-5 & 28 & 28.5 \\
WA-12.5 & 25 & 28.5 \\
\hline
\end{tabular}

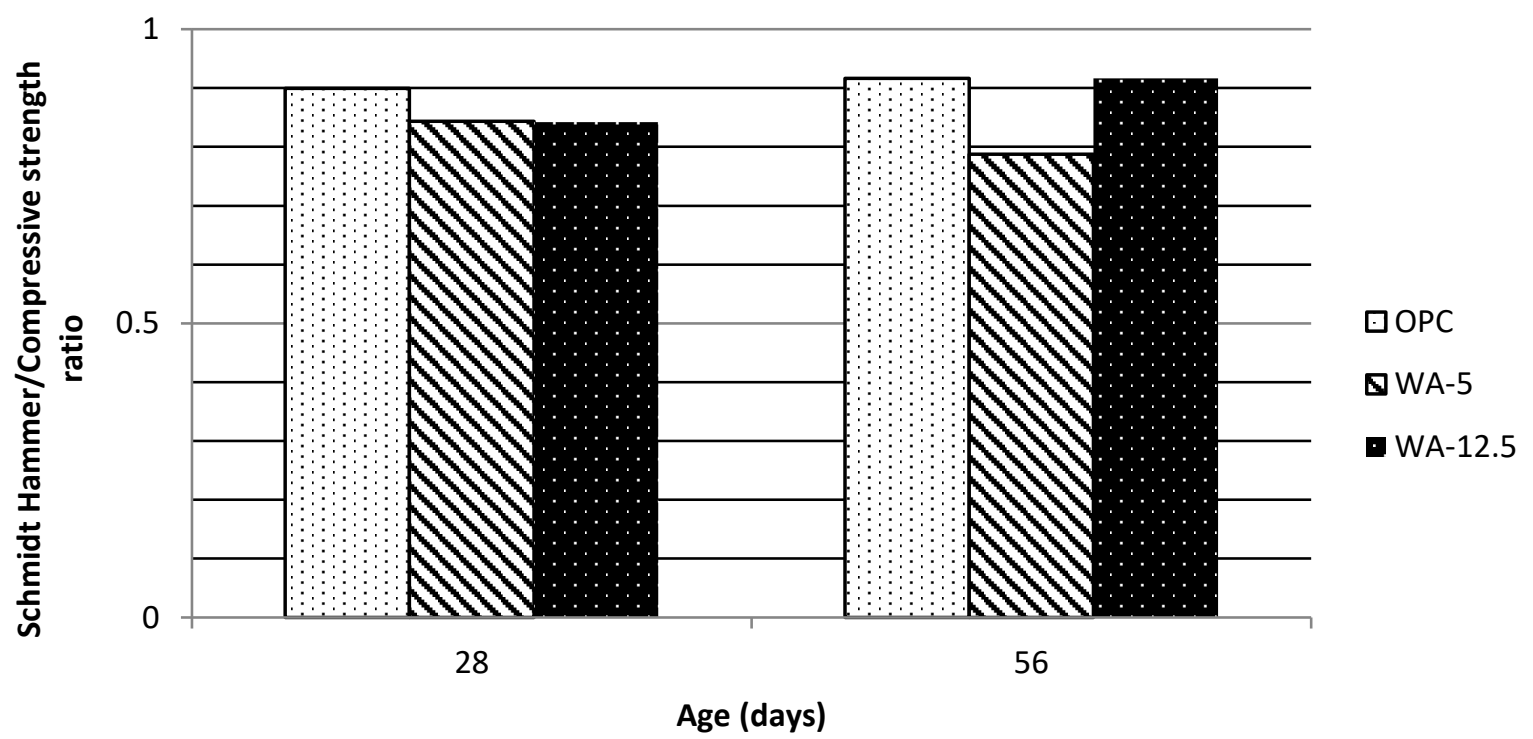

Figure 4. Schmidt Hammer/Compressive cube strength ratio

\subsubsection{Thermal Conductivity}

Thermal conductivity values are presented in Table 5. It can be seen from the results that thermal conductivity values tend to decrease as the age increases. In addition to that, OPC mix indicated lower thermal conductivity values than WA included mixes. This is in contrast with Kizinievic (2016). Kizinievic (2016) stated that WA addition reduced thermal conductivity. Thermal conductivity values were observed to increase as the WA content increases but these differences were observed to be improved at 56 days compared to 28 days. This is in line with compressive strength results WA incorporation provides more Calcium silicate hydrate gel through pozzolanic reactions and results in dense microstructure. Even though Kizinievic (2016) reported WA 
mixes indicated lower thermal conductivity than reference mix, the results present in this study in line with his statement that higher density and compressive strength results in lower thermal conductivity.

Table 5. Thermal conductivity values

\begin{tabular}{ccc}
\hline Concrete Mix & \multicolumn{2}{c}{ Thermal conductivity $(\boldsymbol{\lambda}(\mathbf{W} / \mathbf{m K}))$} \\
& 28-days & 56-days \\
\hline OPC & 0.0440 & 0.0388 \\
WA-5 & 0.0500 & 0.0400 \\
WA-12.5 & 0.0562 & 0.0438 \\
\hline
\end{tabular}

\subsubsection{Ultra Pulse Velocity (UPV)}

Test results for UPV test are seen in Table 6. It is obvious from the results that UPV values decreased as the WA content incremented. This is in contrast with Cheah (2017) whereas addition of WA was observed to increase UPV value. The reduction between OPC and WA mixes was lowered at 56 days compared to 28 days. This is consistent with compressive strength, thermal conductivity and sound permeability test results which indicate that improvement in the pore structure was observed for WA added mixes at 56 days. It is also reported by Cheah (2017) that denser microstructure results in higher UPV values.

Table 6. Ultra pulse velocity test results

\begin{tabular}{ccc}
\hline Concrete Mix & \multicolumn{2}{c}{ Ultra Pulse Velocity } \\
& 28-days & 56-days \\
\hline OPC & 3225 & 4699 \\
WA-5 & 3012 & 4546 \\
WA-12.5 & 2958 & 4445 \\
\hline
\end{tabular}

\subsubsection{Sound Permeability}

Sound permeability results are provided in Table 7. As seen from the results that WA mixes indicated better results compared to conventional mix. This trend was observed at both ages. The results were observed to decrease at 56 days than 28 days. This is due to hydration provided from 28 to 56 days resulted more porous matrix of mixes. Even though, compressive strength, thermal conductivity and UPV test favour OPC slightly in terms of pore structure, these performances of WA mixes can be attributed to better acoustic absorbing characteristics of WA compared to OPC.

Table 7. Sound permeability values

\begin{tabular}{ccc}
\hline Concrete Mix & \multicolumn{2}{c}{ Sound permeability (\%) } \\
& 28-days & 56-days \\
\hline OPC & 30.3 & 26.1 \\
WA-5 & 25 & 23.4 \\
WA-12.5 & 30 & 22.3 \\
\hline
\end{tabular}




\subsubsection{Sulfate resistance}

The values for resistance to sulfate can be seen in Figure 5. Results were obtained as $2.5 \%, 3.9 \%$ and $6.6 \%$ for OPC, 5-WA and 12.5-WA mixes respectively. It is clear from the results that WA addition reduced the resistance to concrete. This is believed to be due to the pore structure of WA concretes.

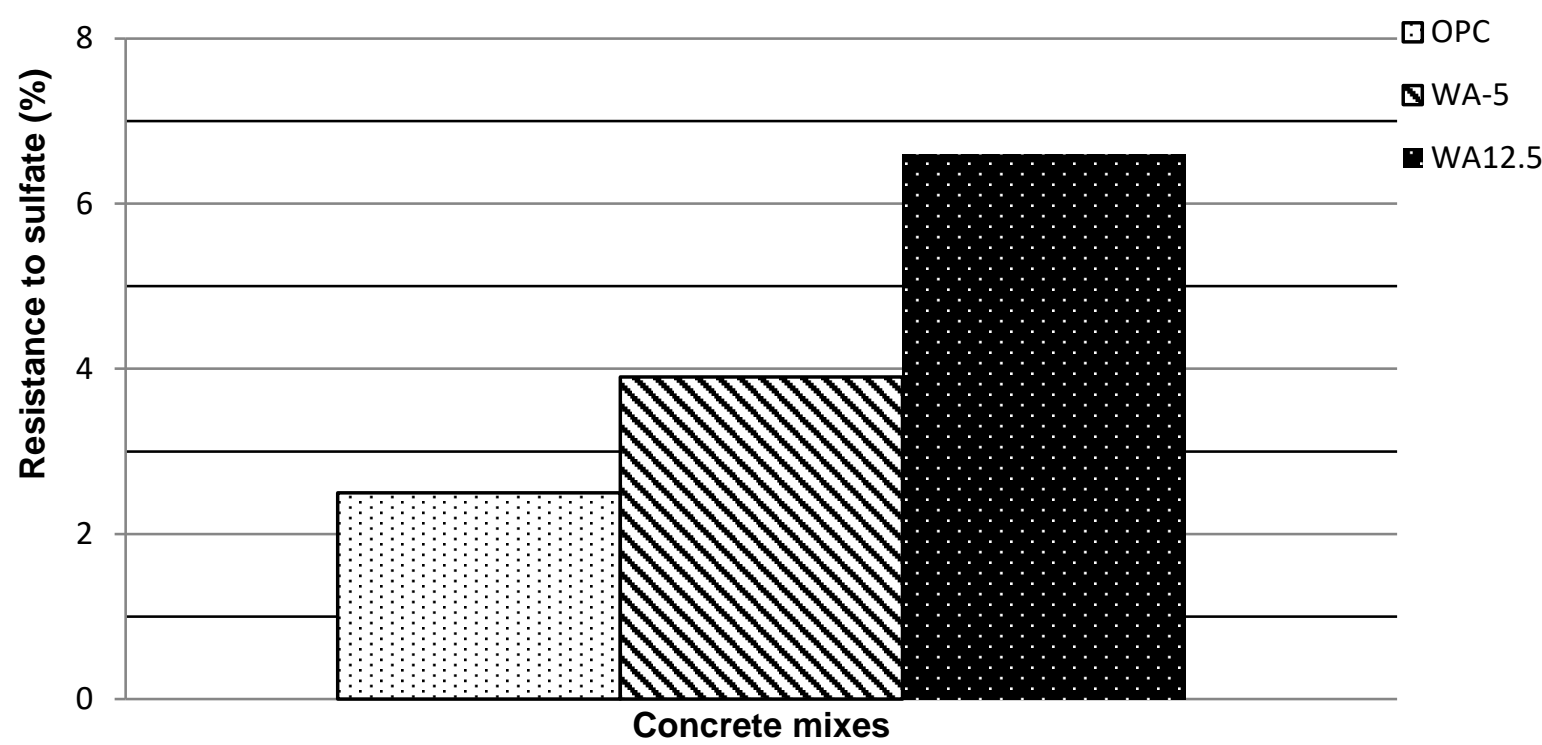

Figure 5. Resistance to sulfate test results

\section{ENVIROMENTAL CONSIDERATIONS}

The use of WA in concrete production will reduce the environmental footprint of concrete. Due to small territory of Northern Cyprus, it is extremely important to consider the effective usage of waste materials or re-use them for other applications as carried out in this research. The utilisation of WA in concrete for the optimum performance will reduce the amount of waste sent to landfill. In addition, it will lead to reduction of OPC content, the main contributor of $\mathrm{CO}_{2}$ emissions amongst concrete constituents. Thus, this will also lower the demand of natural resource extraction whereas it is one of the biggest environmental concerns of the public.

\section{CONCLUSIONS AND RECOMMENDATIONS}

Within this study, it was shown that the utilisation of WA in concrete production can provide quite similar or slightly lower values as OPC mixes. It is monitored from the results that WA addition has a potential to improve mechanical properties at longer ages through hydration.

The main contributions are as follows;

- Similar workabilities can be achieved for WA concretes with less admixture content, for the same workability class.

- WA addition reduces the concrete density slightly. 
- WA concretes have slightly higher thermal conductivity than OPC mix, but is expected to provide either similar or improved values at further ages,

- Compressive strength, thermal conductivity and UPV test results at 28 and 56 days indicates the refinement in the pore structure for WA incorporated mixes.

- WA seems to have better sound absorption properties compared to OPC.

- More environmentally friendly concrete, on local basis, can be achieved in North Cyprus through utilising WA as a replacement to OPC. More research is recommended to find the optimum value for WA replacement level. In addition, waste sent to landfill can also be reduced.

\section{ACKNOWLEDGEMENT}

The author would like to appreciate Mrs. Tuğçe Mani and her firm Boğaziçi Endüstri Madencilik Ltd. and Mr. Metin Eray and his firm Nayat Yap1 Ltd. for providing some of the materials used for present work.

\section{REFERENCES}

- Abdullahi, M. (2006) Characteristics of wood ash/OPC concrete. Leonard Electronic Journal of Practices and Technologies. 8, pp.9-16.

- Allwood, J.M., Cullen, J.M.\& Milford, R.L. (2010) Options for Achieving a $50 \%$ Cut in Industrial Carbon Emissions by 2050. Environmental Science \& Technology. 44. pp.1888-1894.

- Ban, C.C. \& Ramli, M. (2011) The implementation of wood waste ash as a partial cement replacement material in the production of structural grade concrete and mortar: an overview. Resources Conservation and Recycling. 55, pp.669-85.

- Cheah, B.C., Ken Part, W. and Ramli, M. (2017) The long term engineering properties of cementless building block work containing large volume of wood ash and coal fly ash. Construction and Building Materials. 143, pp.522-536.

- Columbia University (2012) Columbia University in the city of New York. [online]. New York: Columbia University. [cited at 1st September 2018]. $<$ https://blogs.ei.columbia.edu/2012/05/09/emissions-from-the-cementindustry/>.

- da Luz Garcia, M. \& Sosa-Couthinho, J. (2013) Strength and durability of cement with forest waste bottom ash. Construction and Building Materials. 41, pp.897-910.

- Kizinievic, O. \& Kizinievic, V. (2016) Utilization of wood ash from biomass for the production of ceramic products. Construction and Building Materials. 127, pp.264-273.

- Ramos, T., Matos, A.M. \& Sosa-Coutinho, J. (2013) Mortar with wood waste ash: Mechanical strength carbonation resistance and ASR expansion. Construction and Building Materials. 49, pp.343-351.

- Siddique, R. (2012) Utilization of wood ash in concrete manufacturing. Resources, Conservation and Recycling. 67, pp.27-33.

- Turkish Standards Institutions. TS EN 206:2013+A1. (2014). Concrete Specification, performance, production and conformity. TSI. Ankara. 
- Turkish Standards Institutions. TS EN 934-2+A1. (2013). Admixtures for concrete, mortar and grout - Part 2: Concrete admixtures - Definitions, requirements, conformity, marking and labelling. TSI. Ankara.

- Udeoyo F.F., Inyang, H., Young, D.T. \& Oparadu, E.E. (2006) Potential of wood waste ash as an additive in concrete. Journal of Materials in Civil Engineering. 18(4). pp.605-611.

- United Nations (2017) UN DESA - United Nations Department of Economic and Social Sciences. [online]. United Nations [cited at 1st September 2018]. $<$ https://www.un.org/development/desa/en/news/population/worldpopulation-prospects-2017.html .

- Usman, M., Khan, A.Y., Farooq, S.H., Hanif, A., Tang, S., Khusnood, R.A. and Rizwan, S.A. (2018) Eco-friendly self compacting cement pastes incorporating wood waste as cement replacement: A feasibility study. Journal of Cleaner Production. 190, pp.679-688. 